\title{
Application of Advanced Machine Learning Approaches to Predict the Compressive Strength of Concrete Containing Supplementary Cementitious Materials
}

\author{
Waqas Ahmad ${ }^{1, *}$, Ayaz Ahmad ${ }^{1,2, *}$, Krzysztof Adam Ostrowski ${ }^{2} \mathbb{D}$, Fahid Aslam ${ }^{3} \mathbb{D}$, Panuwat Joyklad $^{4}$ and \\ Paulina Zajdel ${ }^{2}$ (D) \\ 1 Department of Civil Engineering, COMSATS University Islamabad, Abbottabad 22060, Pakistan \\ 2 Faculty of Civil Engineering, Cracow University of Technology, 24 Warszawska Str., 31-155 Cracow, Poland; \\ krzysztof.ostrowski.1@pk.edu.pl (K.A.O.); paulina.zajdel@doktorant.pk.edu.pl (P.Z.) \\ 3 Department of Civil Engineering, College of Engineering in Al-Kharj, Prince Sattam bin Abdulaziz University, \\ Al-Kharj 11942, Saudi Arabia; f.aslam@psau.edu.sa \\ 4 Department of Civil and Environmental Engineering, Faculty of Engineering, Srinakharinwirot University, \\ 63 Mou 6, Rangsit-Nakhonnayok Rd., Khong 16, Ongkharak District, Nakhon Nayok 26120, Thailand; \\ panuwatj@g.swu.ac.th \\ * Correspondence: waqasahmad@cuiatd.edu.pk (W.A.); ayazahmad@cuiatd.edu.pk (A.A.)
}

Citation: Ahmad, W.; Ahmad, A.; Ostrowski, K.A.; Aslam, F.; Joyklad, P.; Zajdel, P. Application of Advanced Machine Learning Approaches to Predict the Compressive Strength of Concrete Containing Supplementary Cementitious Materials. Materials 2021, 14, 5762. https://doi.org/ $10.3390 /$ ma14195762

Academic Editors: Jian-Guo Dai, Mehran Khan, Majid Ali and Mingli Cao

Received: 20 August 2021

Accepted: 29 September 2021

Published: 2 October 2021

Publisher's Note: MDPI stays neutral with regard to jurisdictional claims in published maps and institutional affiliations.

Copyright: (c) 2021 by the authors. Licensee MDPI, Basel, Switzerland. This article is an open access article distributed under the terms and conditions of the Creative Commons Attribution (CC BY) license (https:// creativecommons.org/licenses/by/ $4.0 /)$.

\begin{abstract}
The casting and testing specimens for determining the mechanical properties of concrete is a time-consuming activity. This study employed supervised machine learning techniques, bagging, AdaBoost, gene expression programming, and decision tree to estimate the compressive strength of concrete containing supplementary cementitious materials (fly ash and blast furnace slag). The performance of the models was compared and assessed using the coefficient of determination $\left(R^{2}\right)$, mean absolute error, mean square error, and root mean square error. The performance of the model was further validated using the k-fold cross-validation approach. Compared to the other employed approaches, the bagging model was more effective in predicting results, with an $\mathrm{R}^{2}$ value of 0.92 . A sensitivity analysis was also prepared to determine the level of contribution of each parameter utilized to run the models. The use of machine learning (ML) techniques to predict the mechanical properties of concrete will be beneficial to the field of civil engineering because it will save time, effort, and resources. The proposed techniques are efficient to forecast the strength properties of concrete containing supplementary cementitious materials (SCM) and pave the way towards the intelligent design of concrete elements and structures.
\end{abstract}

Keywords: machine learning; concrete; supplementary cementitious materials; fly ash; blast furnace slag; compressive strength

\section{Introduction}

Concrete is one of the most frequently used materials in construction worldwide [1-6]. The universality of concrete is due to a number of factors, including their ease of acquisition, resistance to water and heat, and adaptability to a variety of sizes and shapes [7-15]. However, the production of concrete and its ingredients require a considerable amount of energy, consume natural resources, and release $\mathrm{CO}_{2}$ [16,17]. Supplementary cementitious materials (SCMs) are used in concrete to help reduce $\mathrm{CO}_{2}$ emissions [18-24]. Therefore, the utilization of SCMs in concrete could be an effective and sustainable approach. Fly ash (FA) is considered an SCM that could be used as a partial replacement of cement in concrete. Apart from the environmental benefits associated with waste disposal and $\mathrm{CO}_{2}$ sequestration [25,26], FA enhances workability, lowers the heat of hydration and thermal cracking at an early age in concrete, and enhances the mechanical performance of concrete, particularly at later ages [27]. Fly ash is formed as a result of the combustion of the hard coal in the temperature range $1250-1400^{\circ} \mathrm{C}$. In terms of chemical composition, the fly ash 
corresponds to volcanic ash and rocks, such as pumice and trass. FA is a popular additive for the production of concrete, and is treated as a fine-grained non-organic material with pozzolanic properties. The use of FA in fresh concrete mixture improves the concrete mixture's workability properties and tightness, increases resistance to chemical aggression, and reduces tendencies for draining. FA also delays the mixture binding. As a result of pozzolanic reactions in the long period of time, the durability of concrete with fly ash is higher than the durability of the same concrete made with cement. The delays in binding and concrete hardening help decrease the thermal effects of the hydration of the mixture components. Similarly, blast furnace slag (BFS) can reduce the amount of heat generated during cement hydration and improve the overall performance of concrete, including long-term strength, workability and durability [28]. The BFS is a by-product of pig iron smelting in a blast furnace. Usually, its chemical composition is silicon, aluminum, calcium, magnesium, phosphorus, manganese, sodium, and titanium. It is a material that, when properly crushed and activated, shows binding properties both in the water and in the air. Therefore, it is an essential component of CEM II multi-component Portland cements, CEM III blast furnace cements, and CEM V multi-component cements, and is also used as a type II additive for concrete. When added to concrete, blast furnace slag, similar to fly ash, causes low heat of hydration, higher corrosion resistance, increases the long-term durability of concrete, and improves the concrete mixture's workability properties. Hence, the utilization of FA and BFS in concrete could help reduce $\mathrm{CO}_{2}$ emissions by decreasing the demand for cement and by producing materials with improved mechanical properties.

Supervised machine learning (SML) methods are widely employed in the fields of artificial intelligence and computer science and have an irrefutable impact on engineering. They have quickly achieved popularity in civil engineering, particularly for the prediction of the mechanical strength of materials. SML techniques can be used for prediction results with great accuracy. Ahmad et al. [29] used individual and ensemble machine learning (ML) approaches to foretell the compressive strength (CS) of FA-based concrete. Su et al. [30] compared the accuracy of predictions made using a multi-linear regressor, support vector machine, and artificial neural network to predict the bond strength between fiber-reinforced polymers (FRPs) and concrete. Nguyen et al. [31] forecasted the CS of eco-friendly FA-based geopolymer concrete utilizing ML algorithms. Ahmad et al. [32] predicted the chloride penetration in concrete containing waste material using a decision tree, artificial neural network, and gene expression programming techniques. Gene expression programming was demonstrated to be a more effective prediction technique than other algorithms. However, further exploration is required in this area to better understand and apply these approaches in civil engineering while utilizing different datasets and SML techniques.

Considerable experimental research has been carried out to determine the mechanical properties of SCM-based concrete. However, casting and testing specimens in the laboratory require time, effort, and cost. This study concentrates on applying SML techniques for forecasting the CS of concrete containing FA and BFS. The bagging, Adaptive Boosting (AdaBoost), gene expression programming (GEP), and decision tree (DT) algorithms were used to predict the CS of concrete. Numerous statistical checks, error distribution, and the $\mathrm{k}$-fold cross-validation approaches were involved to ensure that the models perform as expected. The purpose of this research was to apply SML algorithms (bagging and AdaBoost) to predict the CS of 1030 data points of concrete containing FA and BFS. Additionally, this research aimed to compare the performance of bagging and AdaBoost techniques using the coefficient of determination $\left(\mathrm{R}^{2}\right)$ value. To assess in the implementation of both models, statistical checks, error evaluation, including mean absolute error (MAE), mean square error (MSE), and root mean square error (RMSE), $\mathrm{k}$-fold cross-validation, and sensitivity analysis were used. This research could be beneficial for scholars in civil engineering because it allows for the prediction of strength properties without requiring precious time in the laboratory. 


\section{Research Methodology}

\subsection{Data Description}

To produce the predicted output variable, SML algorithms need various input variables $[33,34]$. The data utilized in this work to forecast the CS of concrete using FA and BFS as SCM were derived from the literature [35-38]. A total of eight factors were used as inputs for the models, including cement, FA, BFS, water, superplasticizer, coarse aggregate, fine aggregate, and age, while one variable, CS, was used as an output. The input variables and the number of data points have a significant impact on the model's output $[29,32,39]$. The study used a total of 1030 data points (mixes) for the CS prediction of concrete incorporating FA and BFS. Table 1 shows the descriptive statistical analysis for all the input parameters. Figure 1 shows the relative frequency distribution of each parameter utilized in the mixes.

Table 1. Descriptive analysis of input parameters.

\begin{tabular}{|c|c|c|c|c|c|c|c|c|}
\hline \multirow[b]{2}{*}{ Parameter } & \multicolumn{8}{|c|}{ Input Variable } \\
\hline & $\begin{array}{l}\text { Cement } \\
{\left[\mathrm{kg} / \mathrm{m}^{3}\right]}\end{array}$ & $\begin{array}{c}\text { Blast } \\
\text { Furnace Slag } \\
{\left[\mathrm{kg} / \mathrm{m}^{3}\right]}\end{array}$ & $\begin{array}{l}\text { Fly Ash } \\
{\left[\mathrm{kg} / \mathrm{m}^{3}\right]}\end{array}$ & $\begin{array}{c}\text { Water } \\
{\left[\mathrm{kg} / \mathrm{m}^{3}\right]}\end{array}$ & $\begin{array}{c}\text { Superplasticizer } \\
{\left[\mathrm{kg} / \mathrm{m}^{3}\right]}\end{array}$ & $\begin{array}{c}\text { Coarse } \\
\text { Aggregate } \\
{\left[\mathrm{kg} / \mathrm{m}^{3}\right]}\end{array}$ & $\begin{array}{c}\text { Fine } \\
\text { Aggregate } \\
{\left[\mathrm{kg} / \mathrm{m}^{3}\right]}\end{array}$ & $\begin{array}{c}\text { Age } \\
\text { [days] }\end{array}$ \\
\hline Mean & 281.17 & 73.90 & 54.19 & 181.57 & 6.20 & 972.92 & 773.58 & 45.66 \\
\hline Standard Error & 3.26 & 2.69 & 1.99 & 0.67 & 0.19 & 2.42 & 2.50 & 1.97 \\
\hline Median & 272.90 & 22.00 & 0.00 & 185.00 & 6.35 & 968.00 & 779.51 & 28.00 \\
\hline Mode & 425.00 & 0.00 & 0.00 & 192.00 & 0.00 & 932.00 & 594.00 & 28.00 \\
\hline Standard Deviation & 104.51 & 86.28 & 64.00 & 21.36 & 5.97 & 77.75 & 80.18 & 63.17 \\
\hline Range & 438.00 & 359.40 & 200.10 & 125.25 & 32.20 & 344.00 & 398.60 & 364.00 \\
\hline Minimum & 102.00 & 0.00 & 0.00 & 121.75 & 0.00 & 801.00 & 594.00 & 1.00 \\
\hline Maximum & 540.00 & 359.40 & 200.10 & 247.00 & 32.20 & 1145.00 & 992.60 & 365.00 \\
\hline
\end{tabular}

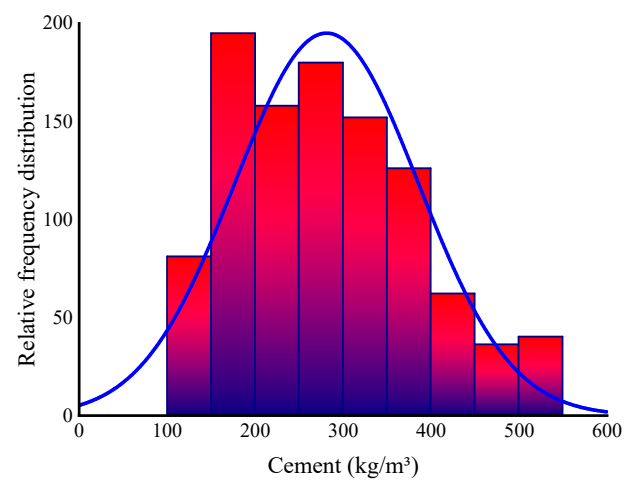

(a)

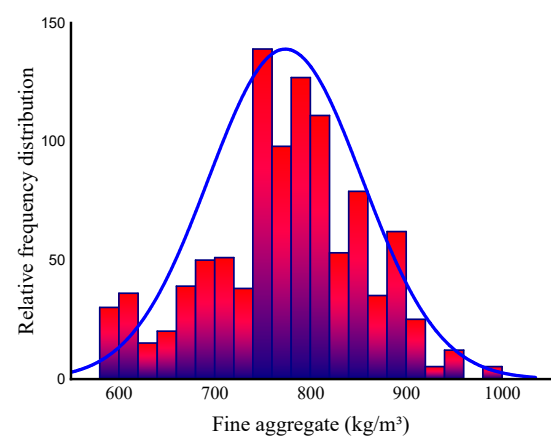

(b)

Figure 1. Cont. 


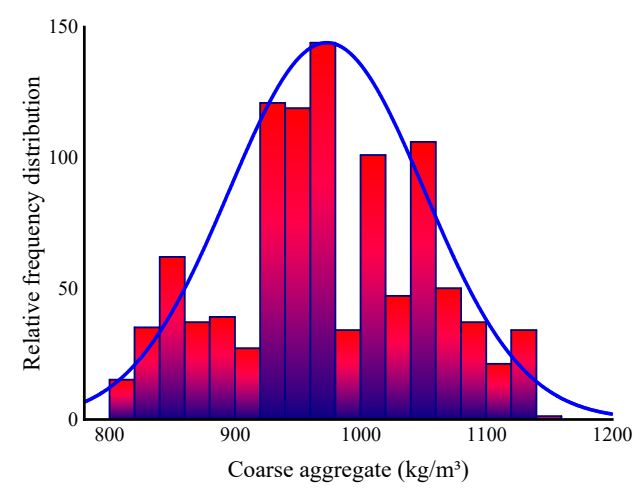

(c)

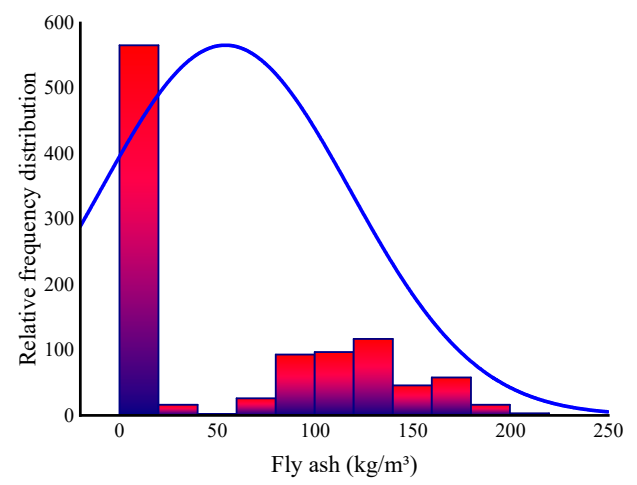

(e)

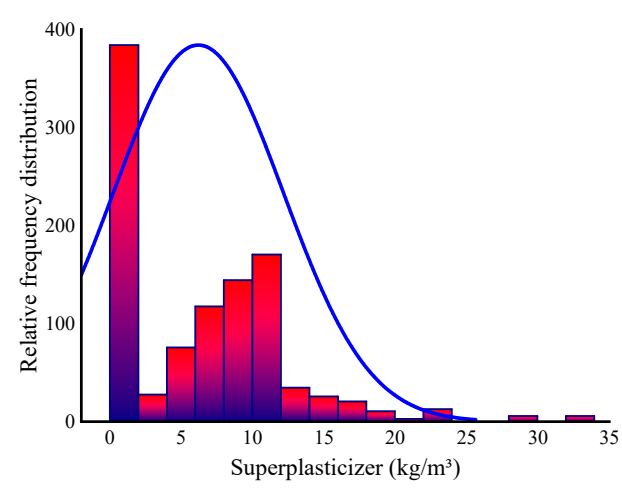

(g)

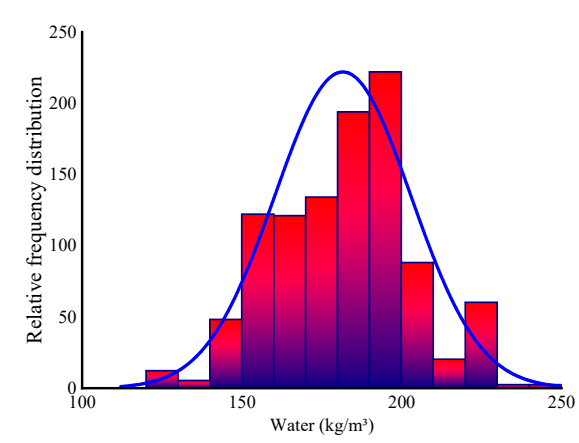

(d)

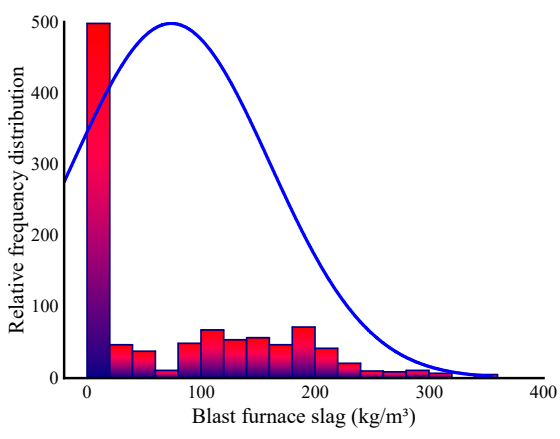

(f)

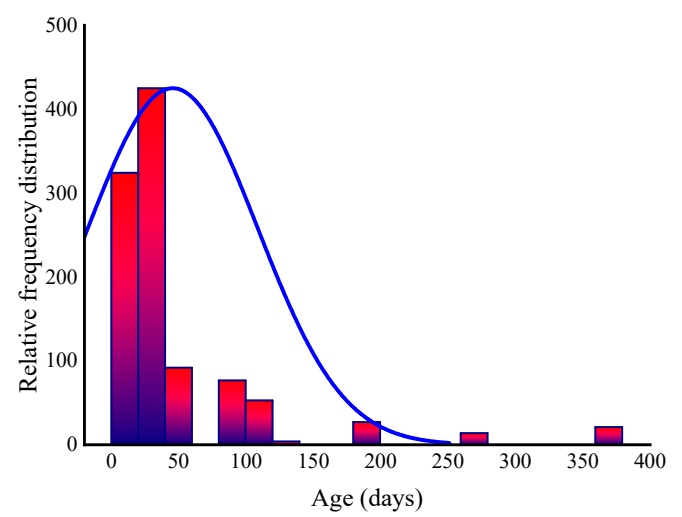

(h)

Figure 1. Relative frequency distribution of input parameters: (a) Cement; (b) Fine aggregate; (c) Coarse aggregate; (d) Water; (e) Fly ash; (f) Blast furnace slag; (g) Superplasticizer; (h) Age.

\subsection{Techniques Employed}

Anaconda software was employed to execute the bagging, AdaBoost, and DT models using Python code. The Anaconda navigator is a desktop graphical user interface incorporate in the Anaconda software, which allows for launching applications that can direct Conda packages, environments, and channels without the need to employ command-line commands. It is also a distribution point of Python and $\mathrm{R}$ programming languages for data science and ML applications that focus on clarifying package development and management. In addition, GEP software was employed to run the GEP model. To estimate the CS of SCM-based concrete, the study used four techniques, namely Bagging, AdaBoost, GEP, and DT. Spyder (version: 4.3.5) was chosen from the Anaconda navigator for running 
the models. The coefficient of determination $\left(R^{2}\right)$ value of the expected outcome from all models indicated the degree of accuracy. The $R^{2}$ values typically range between 0 and 1 , with a larger number indicating more accuracy between the actual and projected results. The ensemble technique is an ML concept that is used to train several models using a similar learning algorithm [40]. The ensemble consists of a large number of algorithms collectively referred to as multi-classifiers. A group of hundreds or thousands of learners with the same goal gets together to resolve the issue.

\subsection{Description of Machine Learning Algorithms}

Bagging is an ensemble method of the parallel kind that explains the variance of the prediction model by providing supplementary data during the training stage. This production is based on irregular sampling, which includes data substitution from the real set. Certain observations can be replicated in each new training data set using sampling with replacement. Each component has an equal chance of appearing in the new dataset in the bagging technique. Increases in the size of the training set have no effect on the predictive force. Additionally, the deviation can be significantly decreased by fine-tuning the forecast to an anticipated result. All these data sets are often utilized for training additional models. This ensemble of various models uses the mean of all the forecasts made by the various models. The prediction in regression can be the mean or average of the predictions from several models [41].

AdaBoost is an SML approach that makes use of ensemble learning. It is also known as adaptive boosting since the weights are re-given to each instance, with increased weights applied to instances that were incorrectly categorized. Boosting techniques are commonly employed in SML to reduce bias and variation. These ensemble approaches are intended to strengthen the weak learner. During the training phase for the input data, an infinite number of DTs are utilized. While constructing the first DT/model, a significant priority is placed on the recorded data that is incorrectly classified throughout the initial model. These data records are the only ones that are utilized as input for another model. The procedure outlined above will be continued until the desired number of basic learners is obtained. On binary classification problems, the AdaBoost regressor outperforms all other regressors in terms of improving the performance of DTs. Furthermore, it is utilized to improve the performance of other machine learning methods. The AdaBoost algorithm provides several advantages when it comes to handling multiple mapping problems. Gradual learning is used to assign different weights to weak classifiers with poor accuracy, and each weak classifier's weight is completely evaluated to produce a high-precision strong classifier [42,43].

Decision tree (DT) is a supervised ML method that is used to solve regression and classification issues. The DT is a tool that visualizes a tree-like model of decisions and their feasible outcomes. The DT's structure is like that of a flowchart, with nodes, branches, and roots. Each internal node displays a test on an attribute, each branch displays the result of the test, and each leaf node displays the class tag. The categorization rule is represented by the path that the root takes to reach the leaf. Three distinct types of DT nodes are accessible, each with a distinct geometric shape (square, circle, and triangle). It is a rather straightforward strategy to comprehend and interpret.

Gene expression programming (GEP) is a transformational algorithm for creating computer programs and modules. These programmers typically contain a tree structure that can change its size (dimensions, shape, and layout), as chromosomes do. As a result, GEP, as a genotype-phenotypic system, can be far more effective than adaptive approaches. GEP's programming language is called Karva and is identical to the LISP languages. GEP has numerous advantages over other classical regression approaches, as other techniques create some functions first and then analyze them. However, no preset function is considered in GEP. In this study, statistical checks, error evaluation, including MAE, MSE, RMSE, $\mathrm{K}$-fold cross-validation, and sensitivity analysis were performed to assess the performance of all the employed models. 
Figure 2 depicts the research approach as a flowchart.

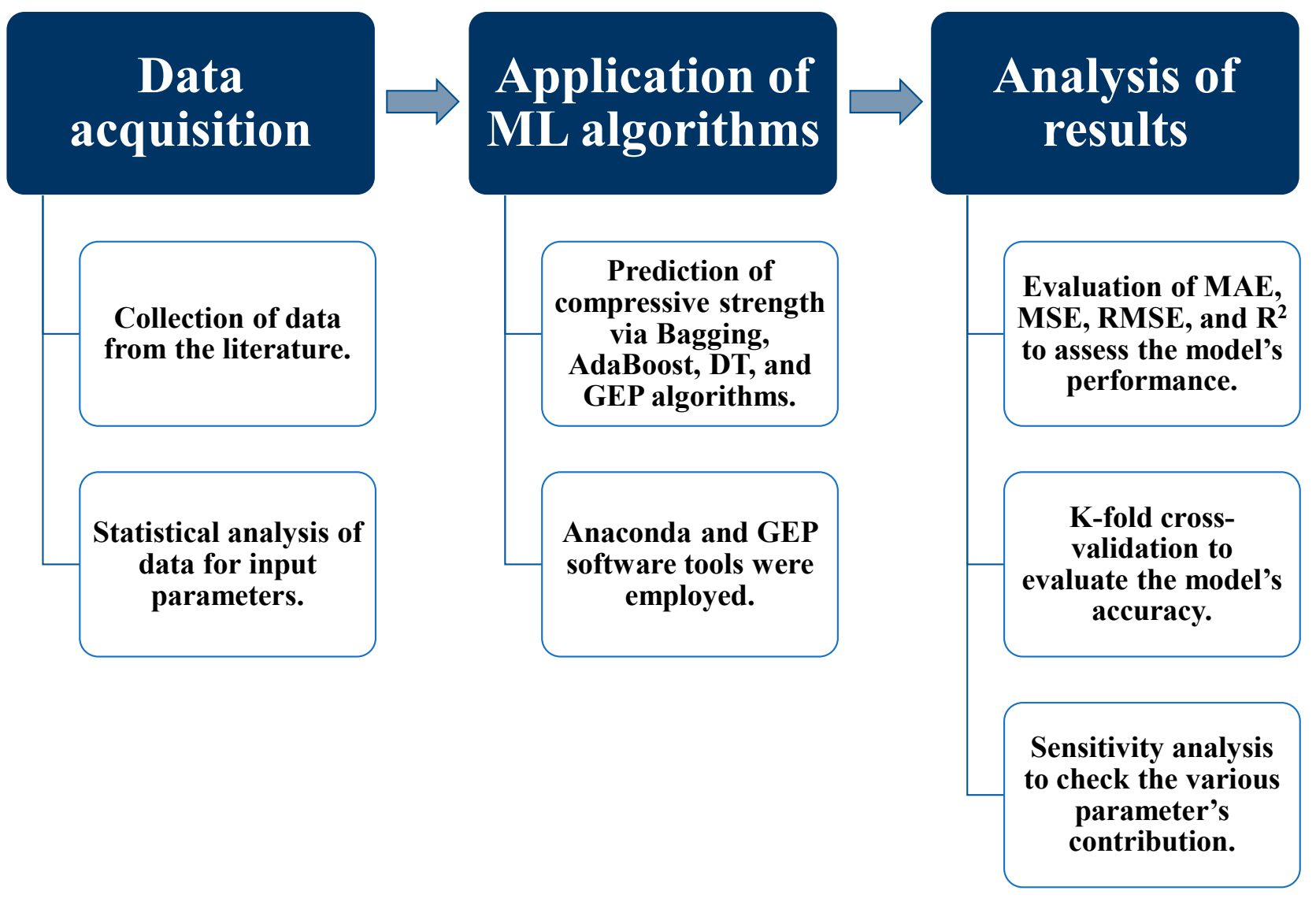

Figure 2. Research methodology flow chart.

3. Results and Analysis

\subsection{Statistical Analysis}

Figure 3 illustrates the statistical analysis interpretation of the real and anticipated results for the CS of SCM-based concrete for the bagging model. The bagging produces output with great precision and a low divergence amongst the real and anticipated values. The $\mathrm{R}^{2}$ value of 0.92 indicates the model's higher accuracy in terms of results prediction. Figure 4 illustrates the scattering of experimental values (targets), predicted values, and errors for the bagging model. The distribution's highest, lowest, and average values were $20.79,0.004$, and $3.26 \mathrm{MPa}$, respectively. However, $26.21 \%$ of the error data were less than $1 \mathrm{MPa}$, whereas $51.94 \%$ of the error data were between 1 and $5 \mathrm{MPa}, 18.45 \%$ were between 5 and $10 \mathrm{MPa}$, and only $3.40 \%$ of the error data were greater than $10 \mathrm{MPa}$.

Figures 5 and 6 illustrate a comparable comparison of actual and anticipated outcomes for the AdaBoost model. The correlation between the actual and projected results is depicted in Figure 5, with an $\mathrm{R}^{2}$ value of 0.82 , which is within an acceptable range with less variation than the bagging model. The distribution of actual values (targets), predicted values, and errors for the AdaBoost model is depicted in Figure 6. The distribution's highest, lowest, and average values were 28.57, 0.020, and 5.13 MPa, respectively. However, $16.99 \%$ of the error values were less than $1 \mathrm{MPa}$, while $43.20 \%$ were between 1 and $5 \mathrm{MPa}, 26.70 \%$ were between 5 and $10 \mathrm{MPa}$, and only $13.11 \%$ were larger than $10 \mathrm{MPa}$. The comparison between bagging and AdaBoost models ( $\mathrm{R}^{2}$ and error distribution) indicated that the bagging model can more accurately predict the CS of SCM-based concrete. Furthermore, twenty sub-models were employed in both techniques to identify the optimal value that results in an uncompromising output result. 


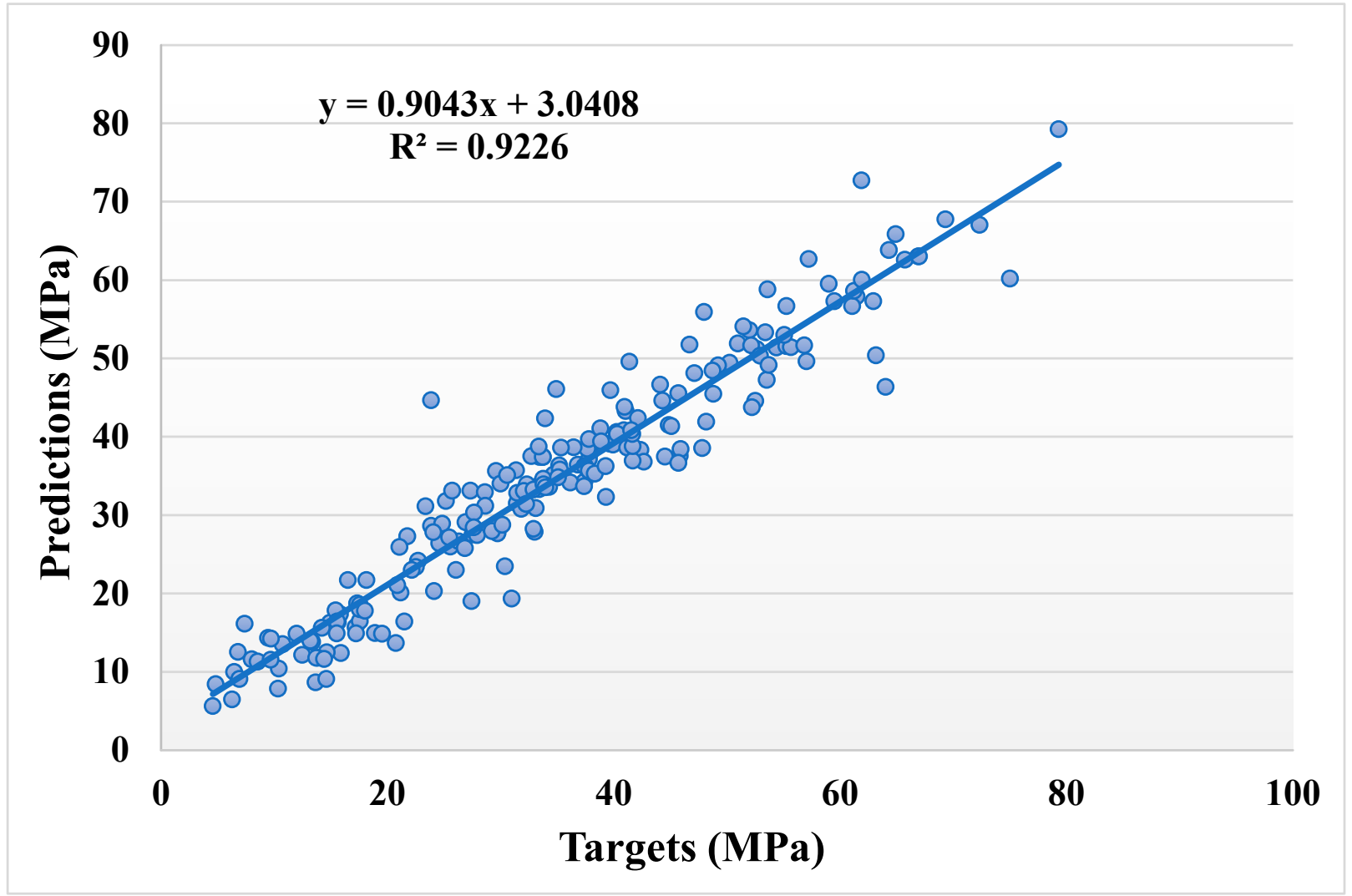

Figure 3. Relationship between the actual and predicted results of the bagging model.

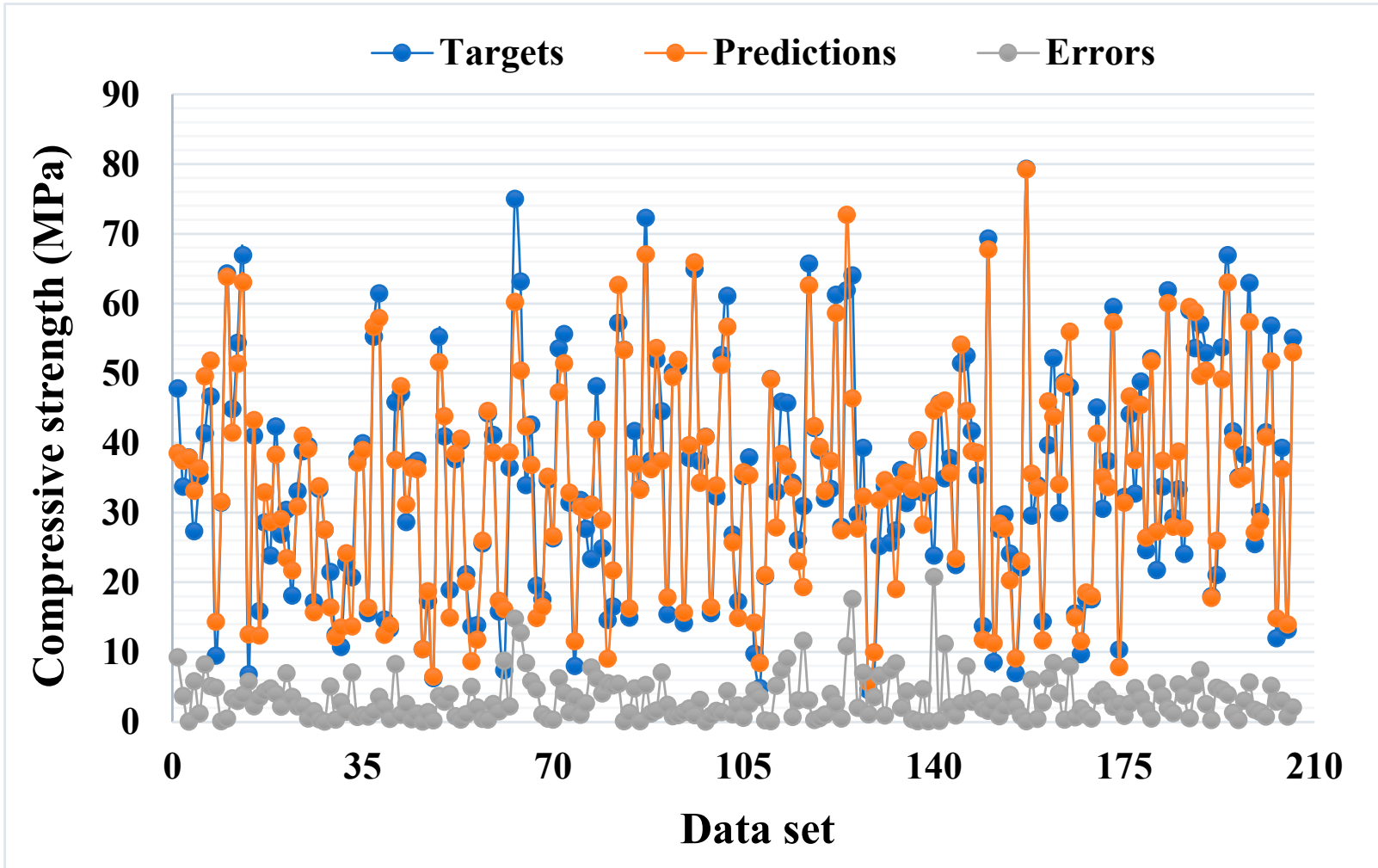

Figure 4. Distribution of actual and predicted values along with the errors for the bagging model. 


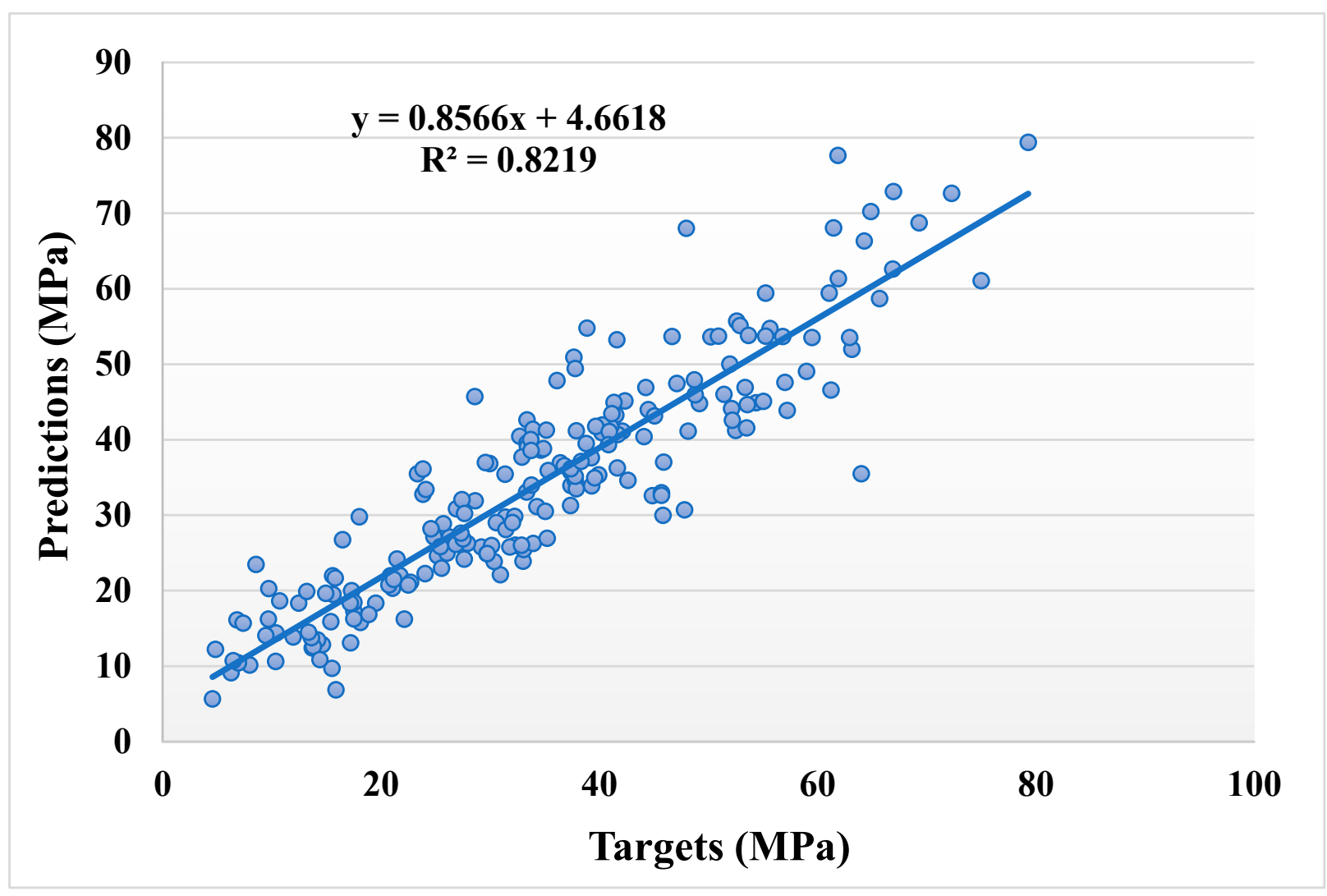

Figure 5. Relationship between the actual and predicted results of the AdaBoost model.

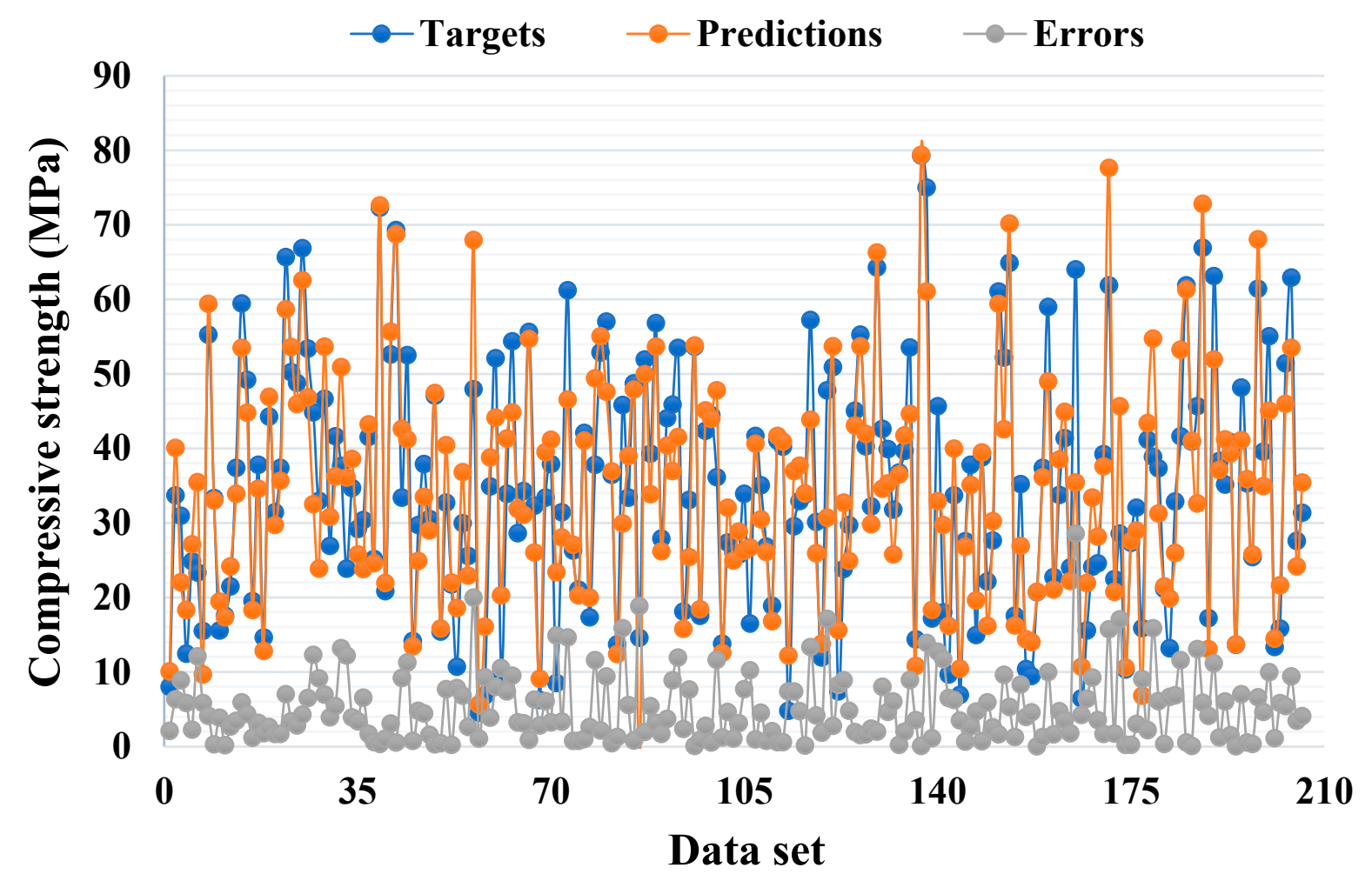

Figure 6. Distribution of actual and predicted values along with the errors for the AdaBoost model. 
Figures 7 and 8 show the comparison between the actual and anticipated outcomes for the GEP model. The correlation between the targeted and projected outcome is shown in Figure 7, indicating the value of $R^{2}$ equals 0.81 , which is also within an acceptable range with less variation. The distribution of actual values (targets), predicted values, and errors for the GEP model can be seen in Figure 8. The error distribution's highest, lowest, and average values were $37.30,0.11$, and $5.24 \mathrm{MPa}$, respectively. We noted that $11.16 \%$ of the error values were between 0 and $1 \mathrm{MPa}, 48.54 \%$ of the error values were between 1 and $5 \mathrm{MPa}, 27.67 \%$ of the error values were between 5 and $10 \mathrm{MPa}$, and only $12.62 \%$ of the error values were above $10 \mathrm{MPa}$. In comparison to the bagging and AdaBoost models, the GEP model's accuracy is less in terms of predicting the CS of SCM-based concrete, as indicated by the $R^{2}$ value.

Figure 9 indicates the statistical analysis interpretation of the actual and forecasted results for the CS of SCM-based concrete for the DT model. The DT also gives the output with lesser accuracy between the targeted and anticipated results. DT models give an $\mathrm{R}^{2}$ value of 0.79 , which indicates the lowest accuracy of the model as compared to the other employed ML approaches. Figure 10 illustrates the scattering of experimental values (targets), predicted values, and errors for the bagging model. We noted that the error distribution's highest, lowest, and average values were $24.05,0.01$, and $5.88 \mathrm{MPa}$, respectively. We observed that $13.11 \%$ of the error values were between 0 and $1 \mathrm{MPa}, 41.75 \%$ of the error values were between 1 and $5 \mathrm{MPa}, 17.96 \%$ of the error values were between 5 and $10 \mathrm{MPa}$, and $20.87 \%$ of the error values were above $10 \mathrm{MPa}$. In comparison, the ensemble ML approaches (bagging and AdaBoost) are more effective for predicting the CS of SCM-based concrete as opposed to the individual ML techniques (GEP and DT), as indicated by their $\mathrm{R}^{2}$ values.

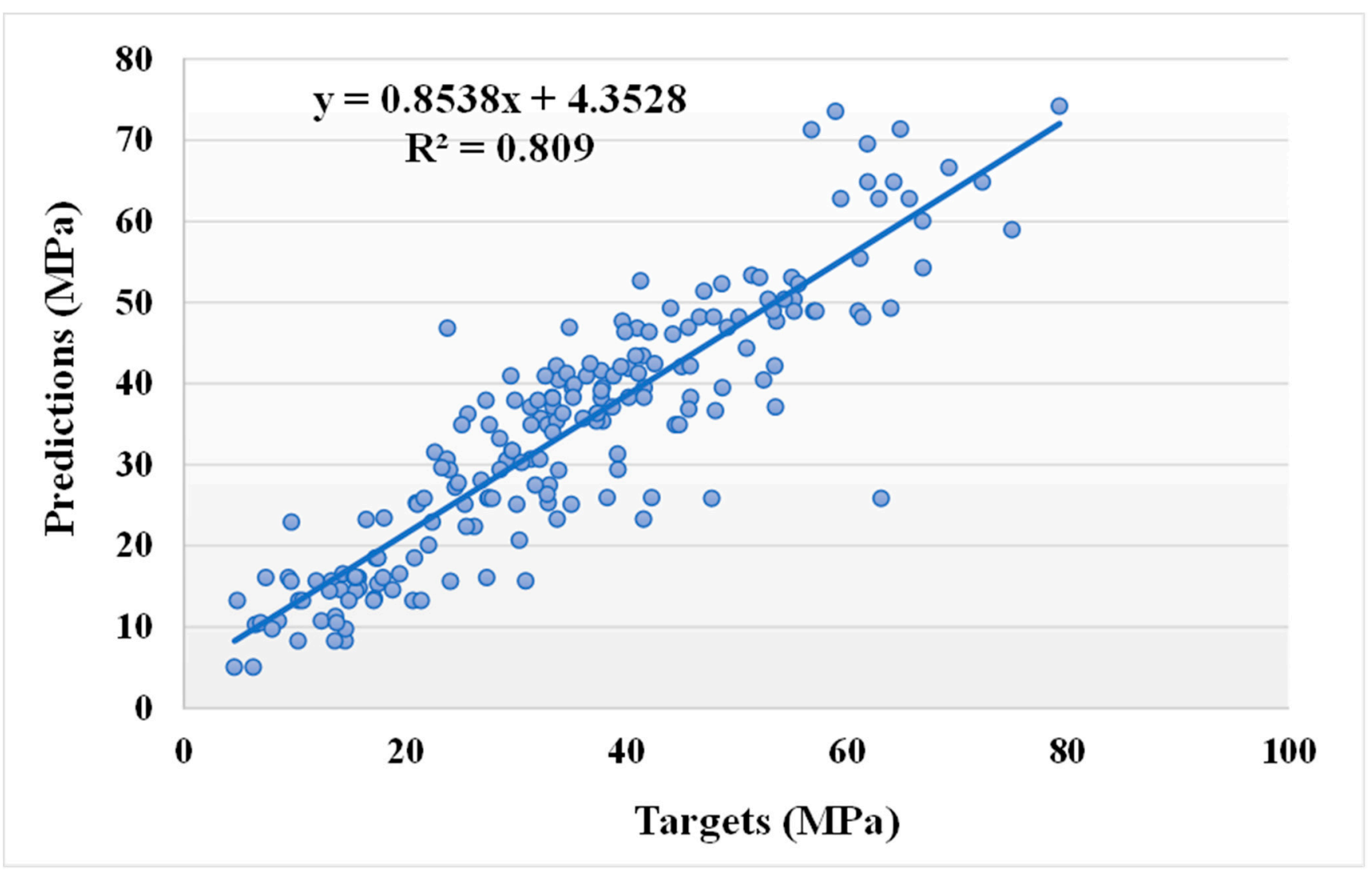

Figure 7. Relationship between the actual and predicted results of the GEP model. 


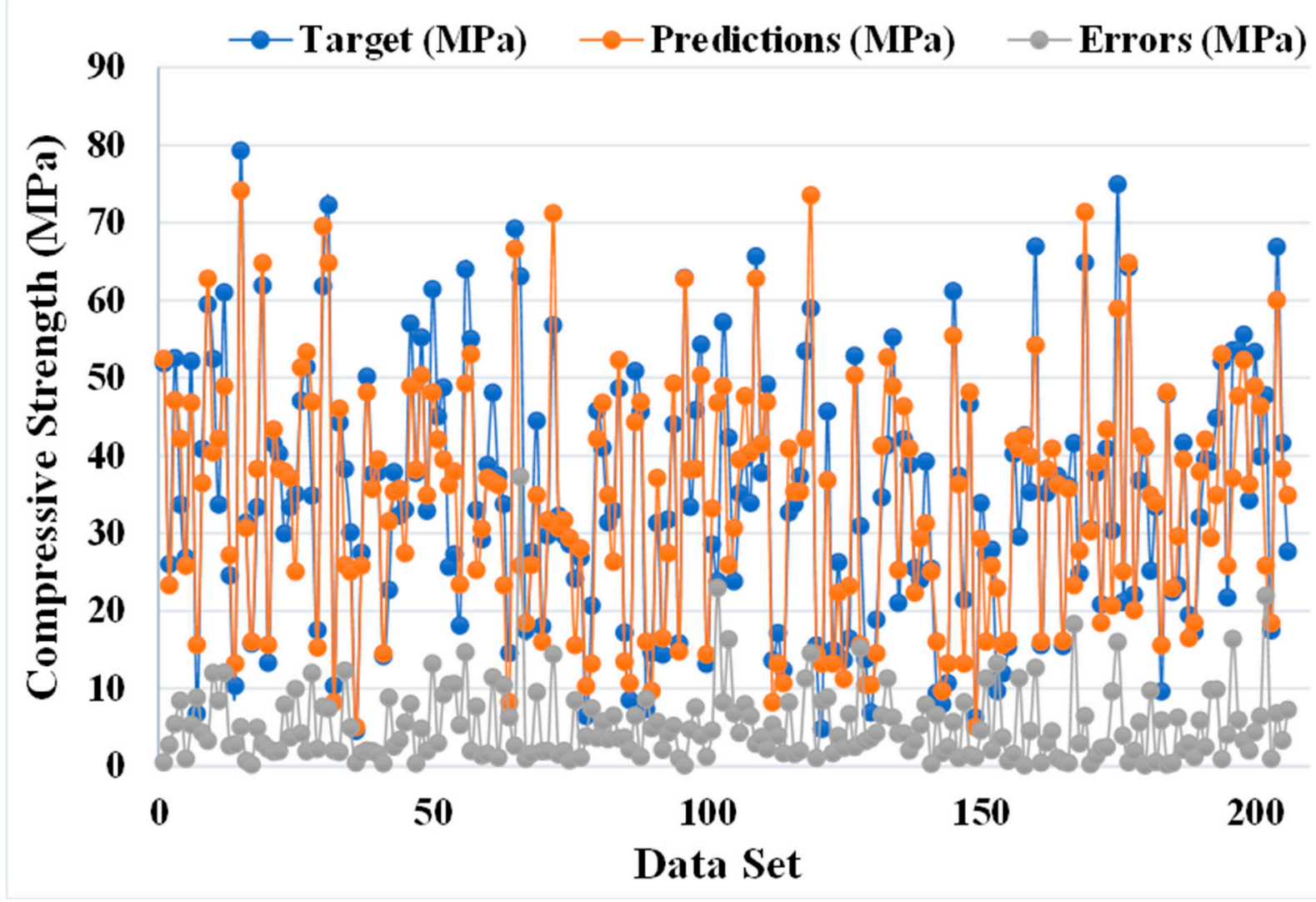

Figure 8. Distribution of actual and predicted values along with the errors for the GEP model.

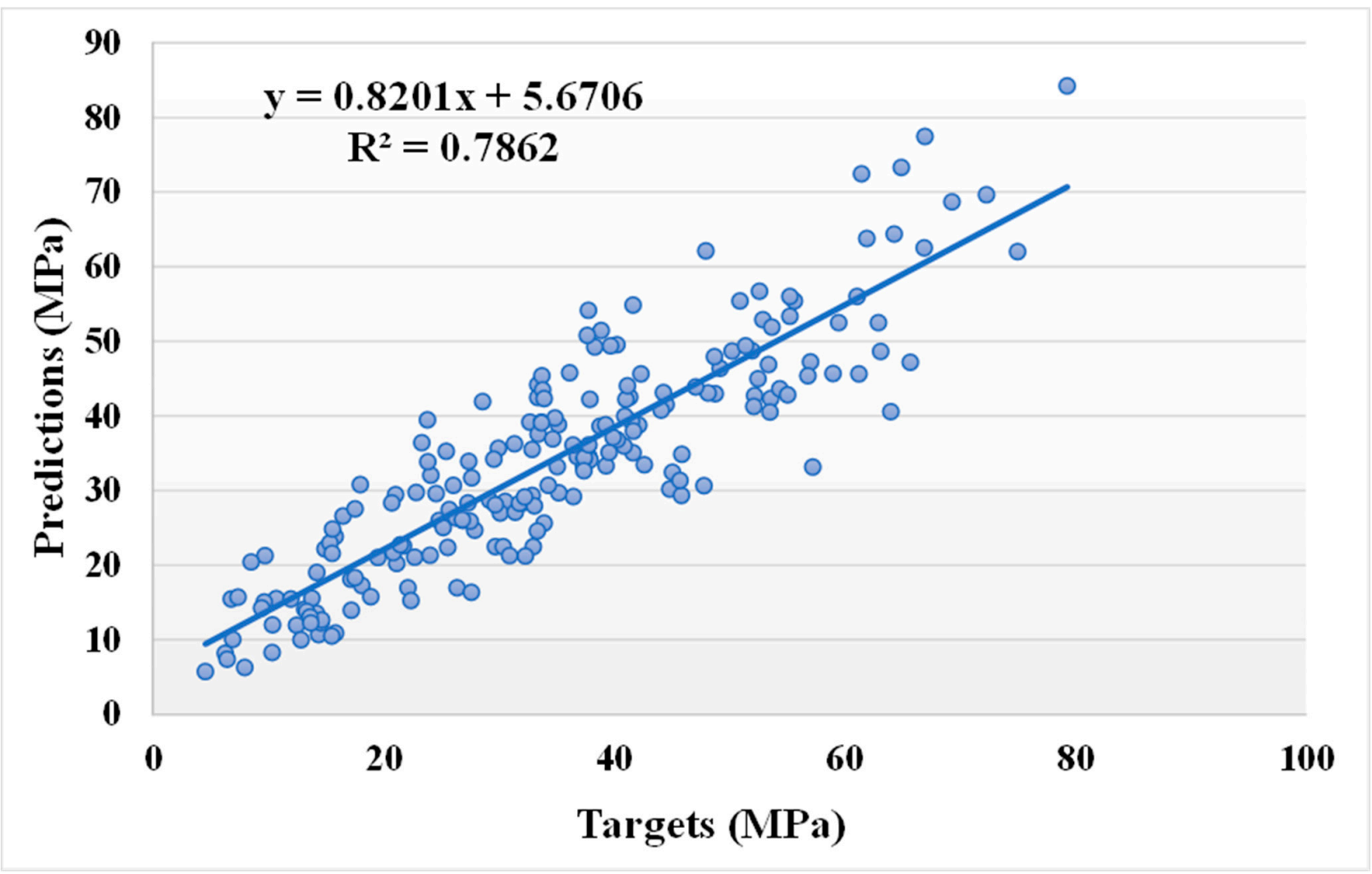

Figure 9. Relationship between the actual and predicted results of the DT model. 


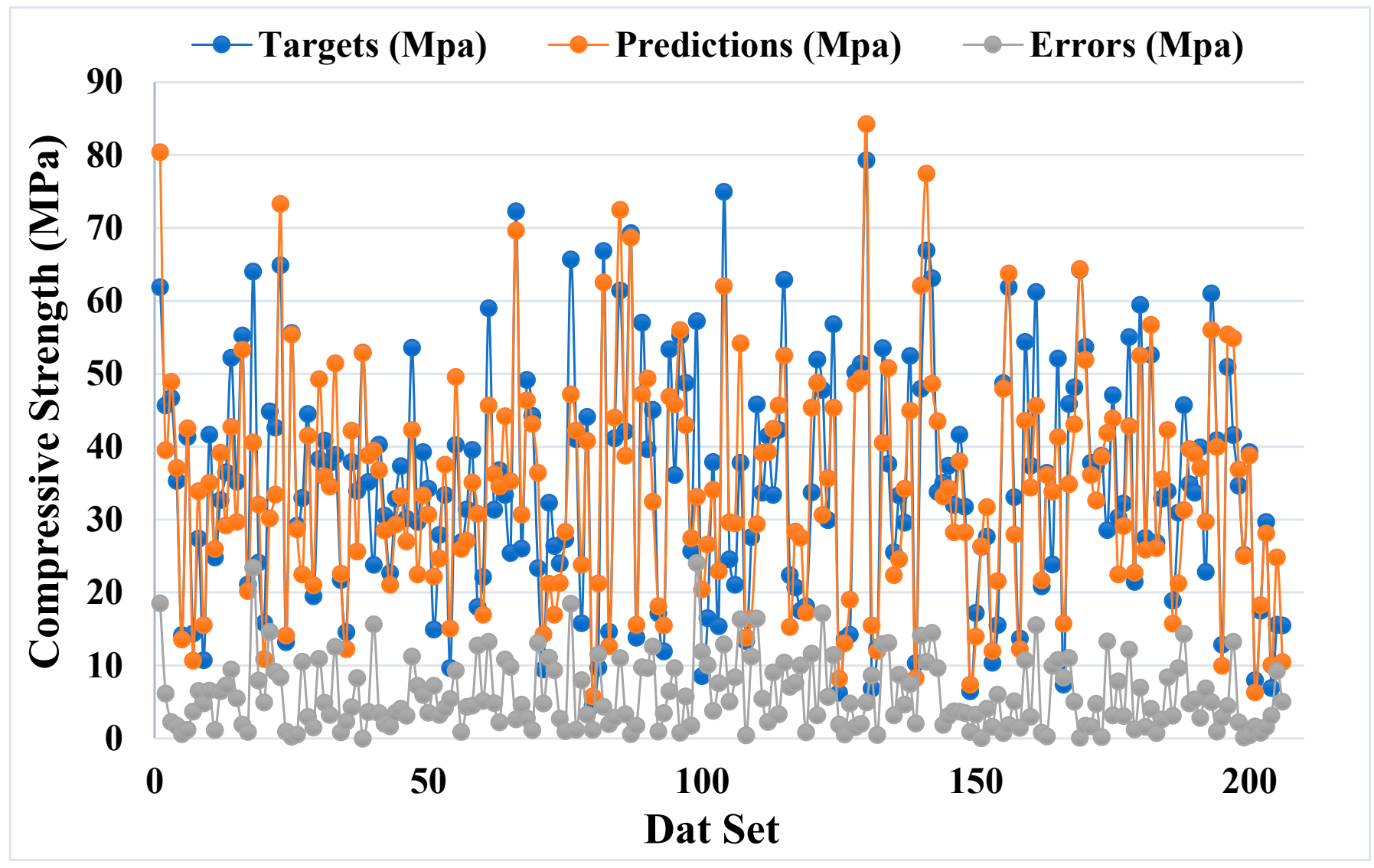

Figure 10. Distribution of actual and predicted values along with the errors for the DT model.

\subsection{K-Fold Cross-Validation}

The k-fold cross-validation approach was used to determine the model's legitimacy during execution. The $\mathrm{k}$-fold cross-validation procedure is typically used to determine the model's validity [33], in which the relevant data are randomly distributed and split into 10 groups. Nine groups are designated for training, and one is designated for validating the model. From the data, $80 \%$ was allocated to train the models, while the remaining $20 \%$ was assigned to test the employed models. The lesser value of the errors (MAE, MSE, RMSE) and the high value of the $\mathrm{R}^{2}$ indicate the model's accuracy. Additionally, the technique needs to be repeated 10 times to achieve an average outcome. This thorough process leads to the model's excellent precision. Furthermore, statistical assessment in the form of errors (MSE, MAE, and RMSE) was performed, as demonstrated in Table 2. The models' reaction to prediction was evaluated through applying statistical analysis using the following Equations (1)-(3), retrieved from the literature [44,45]:

$$
\begin{gathered}
\text { MAE }=\frac{1}{n} \sum_{i=1}^{n}\left|x_{i}-x\right| \\
\text { MSE }=\frac{1}{n} \sum_{i=1}^{n}\left(y_{\text {pred }}-y_{\text {ref }}\right)^{2} \\
\text { RMSE }=\sqrt{\sum \frac{\left(y_{\text {pred }}-y_{\text {ref }}\right)^{2}}{n}}
\end{gathered}
$$

where $n=$ total number of data samples, $x, y_{\text {ref }}=$ reference values in the data sample, and $x_{i}, y_{\text {pred }}=$ predicted values from models. 
Table 2. Statistical checks of the models.

\begin{tabular}{cccc}
\hline Machine Learning Technique & MAE (MPa) & MSE (MPa) & RMSE (MPa) \\
\hline Bagging & 3.257 & 20.566 & 4.535 \\
AdaBoost & 5.126 & 47.376 & 6.883 \\
Gene expression programming & 5.24 & 50.69 & 7.12 \\
Decision tree & 5.88 & 57.30 & 7.57 \\
\hline
\end{tabular}

$\mathrm{R}^{2}$, MAE, MSE, and RMSE were used to evaluate the k-fold cross-validation, and their distributions for bagging, AdaBoost, GEP, and DT models are shown in Table 3. The bagging model with the lowest error and a high $\mathrm{R}^{2}$ value has a better performance in terms of results prediction. The highest, lowest, and average $R^{2}$ values for the bagging model were $0.92,0.58$, and 0.77 , respectively. Comparably, the highest, lowest, and average $\mathrm{R}^{2}$ values for the AdaBoost model were 0.86, 0.40, and 0.68, respectively. Moreover, the MAE, MSE, and RMSE maximum values for the bagging model were 6.44, 93.27, and 9.66 MPa, respectively, whereas the same values for the AdaBoost model were 11.37, 352.19, and 18.77 MPa. The bagging model's minimal MAE, MSE, and RMSE were 3.80, 23.84, and $4.88 \mathrm{MPa}$, respectively, whereas the same value for the AdaBoost model was 5.78, 55.82, and 7.47 MPa. Similar values for GEP and DT models are also listed in Table 3.

Table 3. Results of k-fold cross-validation.

\begin{tabular}{|c|c|c|c|c|c|c|c|c|c|c|c|c|c|c|c|c|}
\hline \multirow{2}{*}{$\begin{array}{c}\text { K- } \\
\text { Fold }\end{array}$} & \multicolumn{4}{|c|}{ Bagging } & \multicolumn{4}{|c|}{ AdaBoost } & \multicolumn{4}{|c|}{ GEP } & \multicolumn{4}{|c|}{ DT } \\
\hline & MAE & MSE & RMSE & $\mathbf{R}^{2}$ & MAE & MSE & RMSE & $\mathbf{R}^{2}$ & MAE & MSE & RMSE & $\mathbf{R}^{2}$ & MAE & MSE & RMSE & $\mathbf{R}^{2}$ \\
\hline 1 & 6.32 & 93.27 & 9.66 & 0.78 & 11.37 & 352.19 & 18.77 & 0.79 & 8.82 & 144.16 & 12.01 & 0.64 & 7.19 & 104.48 & 10.22 & 0.79 \\
\hline 2 & 3.8 & 23.84 & 4.88 & 0.89 & 6.98 & 88.87 & 9.43 & 0.66 & 4.96 & 44.64 & 6.68 & 0.81 & 7.06 & 89.92 & 9.48 & 0.88 \\
\hline 3 & 4.02 & 57.12 & 7.56 & 0.75 & 7.14 & 87.44 & 9.35 & 0.82 & 6.97 & 78.53 & 8.86 & 0.69 & 5.21 & 50.22 & 7.09 & 0.64 \\
\hline 4 & 6.21 & 59.64 & 7.72 & 0.68 & 8.52 & 120.48 & 10.98 & 0.55 & 7.82 & 107.62 & 10.37 & 0.97 & 7.79 & 108.75 & 10.43 & 0.98 \\
\hline 5 & 6.44 & 53.77 & 7.33 & 0.76 & 5.78 & 69.19 & 8.32 & 0.47 & 6.78 & 68.60 & 8.28 & 0.94 & 6.00 & 70.30 & 8.38 & 0.91 \\
\hline 6 & 5.25 & 80.87 & 8.99 & 0.78 & 10.45 & 305.18 & 17.47 & 0.83 & 8.11 & 91.29 & 9.55 & 0.88 & 8.39 & 130.51 & 11.42 & 0.71 \\
\hline 7 & 4.27 & 26.34 & 5.13 & 0.92 & 6.6 & 55.82 & 7.47 & 0.86 & 5.18 & 44.09 & 6.64 & 0.72 & 5.38 & 53.56 & 7.32 & 0.84 \\
\hline 8 & 4.72 & 54.81 & 7.4 & 0.58 & 6.68 & 83.73 & 9.15 & 0.4 & 8.55 & 129.71 & 11.39 & 0.76 & 7.91 & 100.65 & 10.03 & 0.93 \\
\hline 9 & 5.68 & 55 & 7.42 & 0.73 & 7.33 & 92.23 & 9.6 & 0.68 & 9.25 & 154.31 & 12.42 & 0.95 & 5.26 & 48.27 & 6.95 & 0.66 \\
\hline 10 & 4.57 & 47.7 & 6.91 & 0.83 & 5.89 & 56.63 & 7.53 & 0.74 & 6.82 & 79.24 & 8.90 & 0.93 & 5.25 & 58.76 & 7.67 & 0.75 \\
\hline
\end{tabular}

\subsection{Sensitivity Analysis}

This investigation is concerned with the influence of input parameters on forecasting the CS of SCM-based concrete. The input parameters have a considerable impact on the outcome projection [46]. The influence of each input parameter on the CS prediction of concrete is depicted in Figure 11. We noted that age contributed the most $(27.8 \%)$, while cement and superplasticizer contributed $21.7 \%$ and $16.3 \%$, respectively. However, the other variables contributed less, with water contributing $11.5 \%$, coarse aggregate $7.6 \%$, BFS $6.1 \%$, FA $5.8 \%$, and fine aggregate $2.1 \%$ to the prediction of CS of SCM-based concrete. The sensitivity analyses produced results proportional to the number of input parameters and data points utilized to run the model. However, the applied ML method identified the influence of each parameter, and this analysis produced varying results due to the variation in concrete mix proportions and the addition of other input parameters. The following Equations (4) and (5) were used to determine each variable's contribution to the model's output:

$$
\begin{gathered}
N_{i}=f_{\max }\left(x_{i}\right)-f_{\min }\left(x_{i}\right) \\
S_{i}=\frac{N_{i}}{\sum_{j-i}^{n} N_{j}}
\end{gathered}
$$

where, $f_{\max }\left(x_{i}\right)$ and $f_{\min }\left(x_{i}\right)$ are the highest and lowest of the anticipated output over the ith output. 


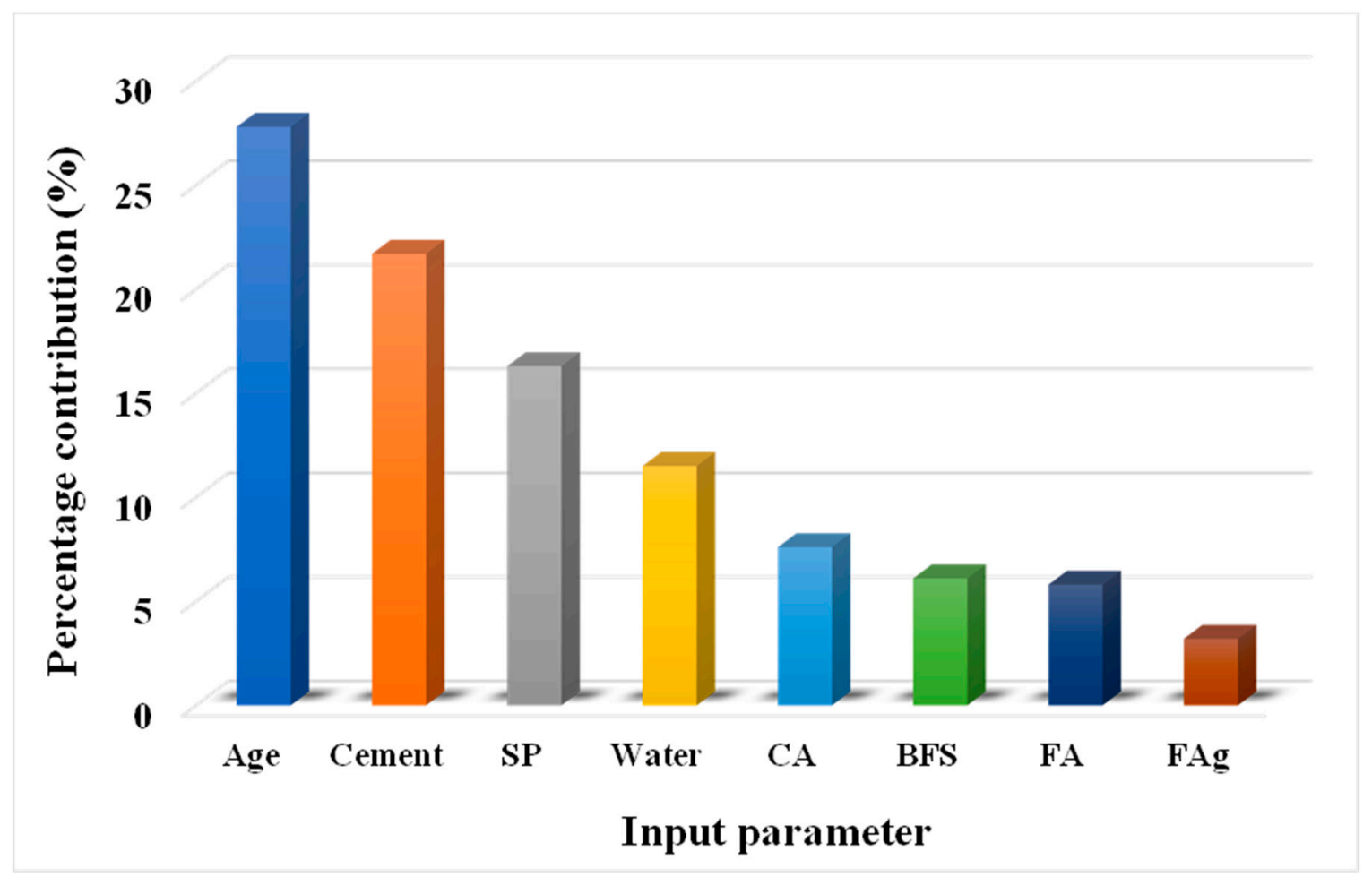

Figure 11. Sensitivity analysis of various contributing parameters towards the prediction. SP: superplasticizer, CA: coarse aggregate, BFS: blast furnace slag, FA: fly ash, FAg: fine aggregate.

\section{Discussions}

The purpose of this study was to demonstrate how SML techniques may be used to predict the CS of concrete incorporating FA and BFS as cement replacements. The purpose of using SCMs in concrete is to create material that is both effective and sustainable. The study employed four ML techniques, namely bagging, AdaBoost, GEP, and DT. To determine which algorithm was the better predictor, the forecast performance of all the employed techniques was contrasted. The bagging model's output was more accurate, exhibiting an $\mathrm{R}^{2}$ value of 0.92 , compared to the AdaBoost, GEP, and DT models indicating $\mathrm{R}^{2}$ values equal to $0.82,0.81$, and 0.79 , respectively. Additionally, the performance of all the models was validated using statistical assessment and the $\mathrm{k}$-fold cross-validation approach. The lower the error levels, the higher performing the model is. However, analyzing and recommending the optimum ML regressor for predicting results for diverse topics is challenging because each model's performance is strongly related to the input parameters and data points used to run the model. However, ensemble ML techniques typically employ the weak learner by constructing sub-models that can be trained on data and optimizing to reach the largest $R^{2}$ value. The distribution of $R^{2}$ values of sub-models for bagging and AdaBoost techniques is depicted in Figures 12 and 13, respectively. We observed that the $\mathrm{R}^{2}$ values for all sub-models of bagging were higher than 0.91 (Figure 12), while the maximum $R^{2}$ value among all the sub-models of AdaBoost was 0.82 (Figure 13). This also supports the higher accuracy of the bagging technique for the prediction of the results. The literature also indicated that bagging models produce more accurate outcomes than other ML approaches [29,46]. Moreover, a sensitivity analysis was performed to determine the impact of each input parameter on the prediction of the CS of SCM-based concrete. The model's performance could be influenced by the input parameters and the amount of data points. The contribution level of each of the eight input parameters to the anticipated result was determined by the sensitivity analysis. 


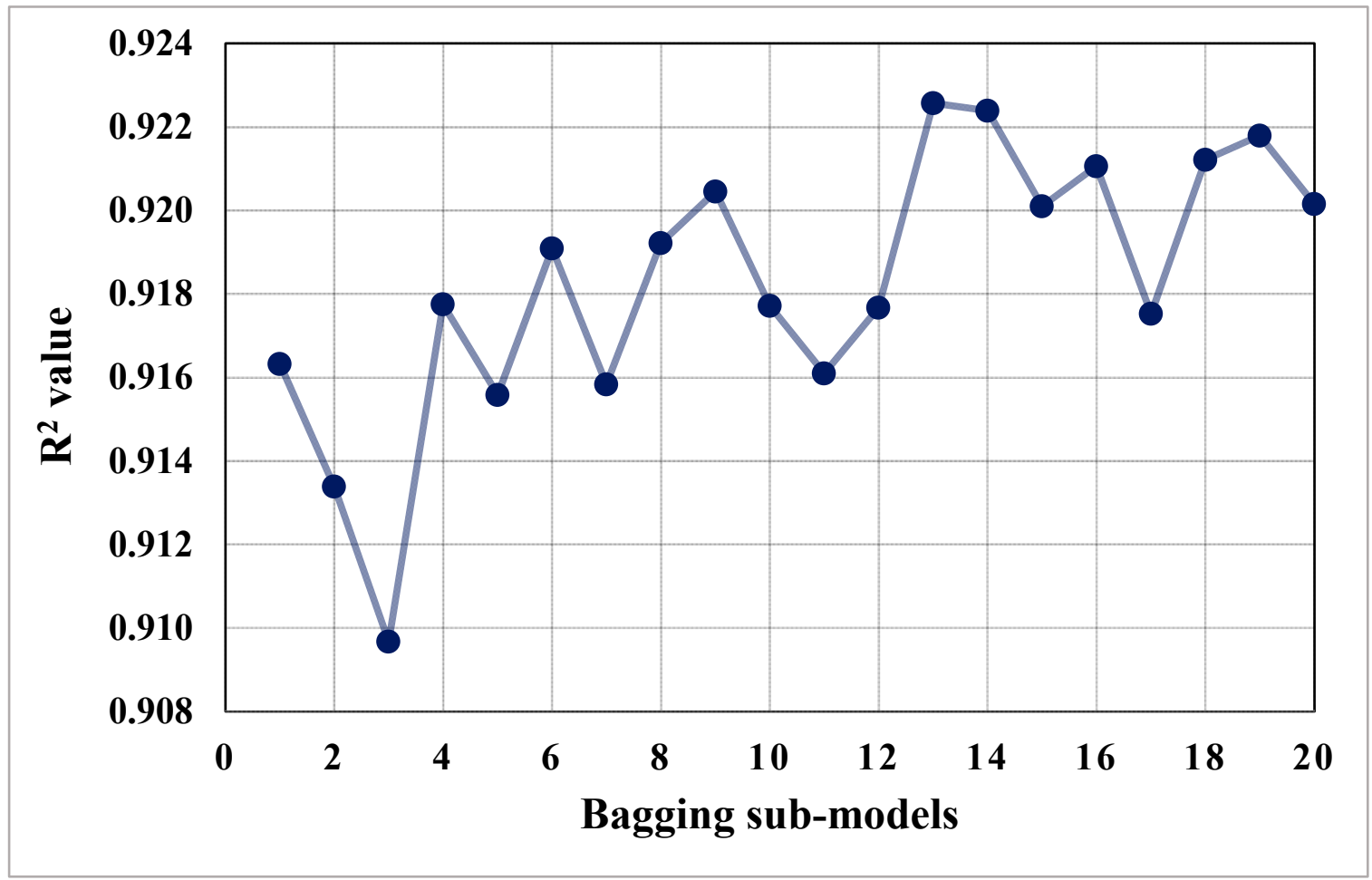

Figure 12. Coefficient of determination $\left(\mathrm{R}^{2}\right)$ values of bagging sub-models.

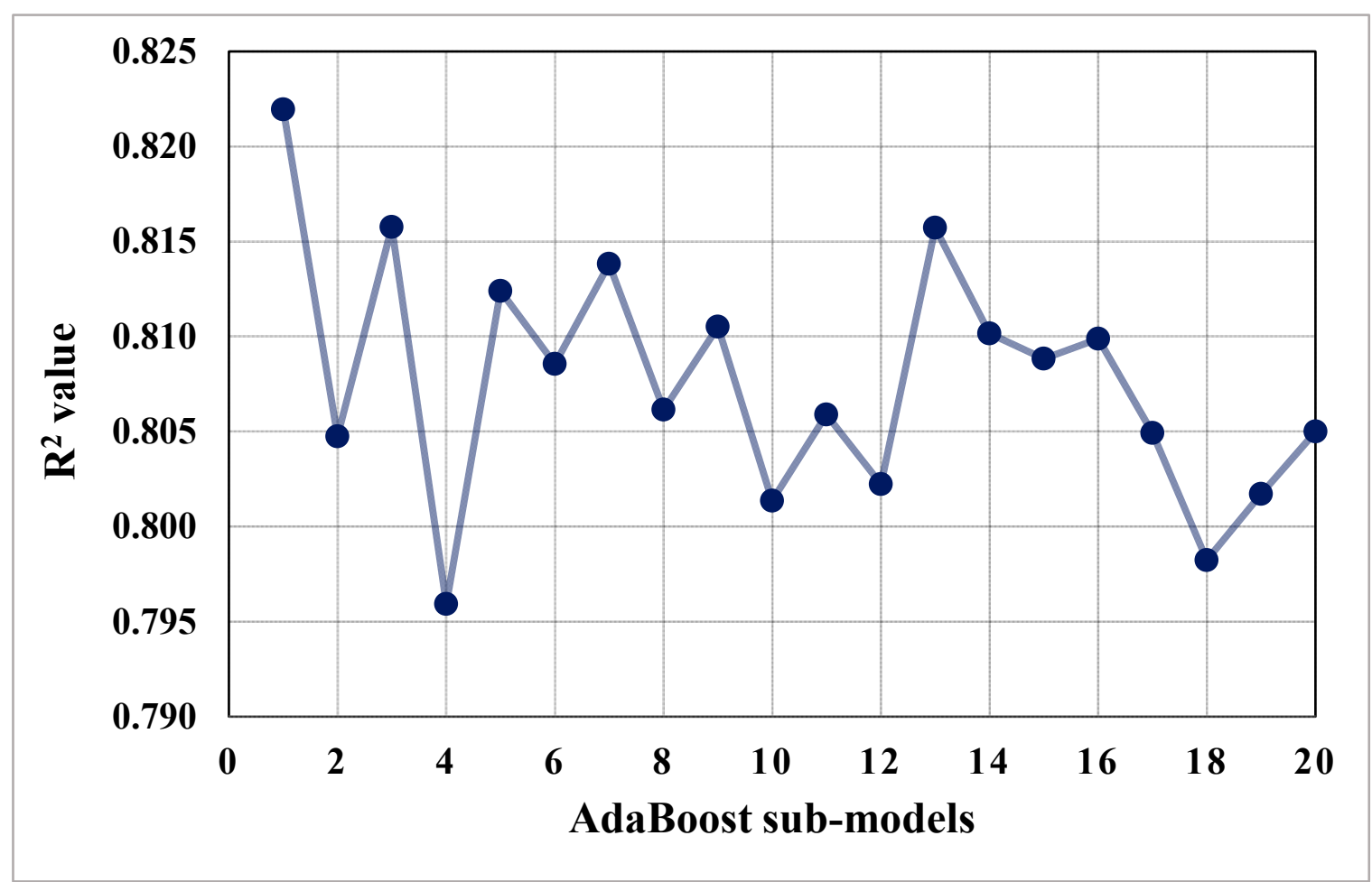

Figure 13. Coefficient of determination $\left(R^{2}\right)$ values of AdaBoost sub-models.

\section{Conclusions}

The objective of this study was to evaluate and demonstrate how supervised machine learning (SML) techniques can be used to forecast the compressive strength of concrete incorporating fly ash and blast furnace slag. The CS of concrete was forecasted using 
bagging, Adaptive Boosting (AdaBoost), gene expression programming (GEP), and decision tree (DT) algorithms. The following conclusions can be drawn:

- The bagging model was more effective at prediction than the other employed models, as evidenced by its better coefficient of determination $\left(R^{2}\right)$ and lower error values. The $\mathrm{R}^{2}$ for the bagging, AdaBoost, GEP, and DT models was noted to be $0.92,0.82,0.81$, and 0.79 , respectively. However, the results of all the models were in the acceptable range.

- Statistical analysis and the $\mathrm{k}$-fold cross-validation method have also proven the satisfactory performance of the employed models. These checks also corroborated the bagging model's superior performance over the other analyzed models.

- Sensitivity analysis of input parameters revealed that coarse aggregate, fine aggregate, and cement contributed $24.7 \%, 18.4 \%$, and $16.2 \%$, respectively, to the prediction of the results, while other input parameters contributed less.

- The SML techniques can forecast the strength properties of concrete with higher accuracy without requiring additional time for sample casting and testing.

The use of both the ensemble (bagging and AdaBoost) and individual (GEP and DT) ML techniques to forecast concrete CS was proposed in this work. It is recommended that other SML techniques be employed to compare their accuracy for the prediction of outcomes. Moreover, data points and the number of outcomes should be expanded through experimental work, field tests, and other numerical analyses utilizing other methodologies (e.g., Monte Carlo simulation) in future studies. Moreover, the input parameters could be enhanced by adding environmental factors (e.g., high temperature and humidity), along with the in-depth explanation of the raw materials to get a better response from the models. In addition, more in-depth analyses, checks, and effects should be incorporated for a better evaluation and understanding of the outcomes from ML techniques.

Author Contributions: W.A.: Conceptualization, writing—original draft \& validation. A.A.: Data curation, software, writing - review \& editing. K.A.O.: resources, supervision \& writing-revised draft. F.A.: Project administration \& methodology. P.J.: Formal analysis \& investigation P.Z.: Visualization \& editing. All authors have read and agreed to the published version of the manuscript.

Funding: This research is supported by Cracow University of Technology, and COMSATS University Islamabad.

Institutional Review Board Statement: Not applicable.

Informed Consent Statement: Not applicable.

Data Availability Statement: Not applicable.

Acknowledgments: This research was funded by the Faculty of Civil Engineering, Cracow University of Technology, and the Department of Civil Engineering, COMSATS University Islamabad, Abbottabad Campus.

Conflicts of Interest: The authors declare no conflict of interest.

\section{References}

1. Amran, M.; Fediuk, R.; Murali, G.; Avudaiappan, S.; Ozbakkaloglu, T.; Vatin, N.; Karelina, M.; Klyuev, S.; Gholampour, A. Fly ash-based eco-efficient concretes: A comprehensive review of the short-term properties. Materials 2021, 14, 4264. [CrossRef] [PubMed]

2. Xu, Q.; Ji, T.; Gao, S.-J.; Yang, Z.; Wu, N. Characteristics and applications of sugar cane bagasse ash waste in cementitious materials. Materials 2018, 12, 39. [CrossRef] [PubMed]

3. Kim, S.S.; Qudoos, A.; Jakhrani, S.H.; Lee, J.B.; Kim, H.G. Influence of coarse aggregates and silica fume on the mechanical properties, durability, and microstructure of concrete. Materials 2019, 12, 3324. [CrossRef] [PubMed]

4. Chu, S.H.; Kwan, A.K.H. Mixture design of self-levelling ultra-high performance FRC. Constr. Build. Mater. $2019,228,116761$. [CrossRef]

5. Khan, M.; Ali, M. Use of glass and nylon fibers in concrete for controlling early age micro cracking in bridge decks. Constr. Build. Mater. 2016, 125, 800-808. [CrossRef] 
6. Khan, M.; Cao, M.; Xie, C.; Ali, M. Hybrid fiber concrete with different basalt fiber length and content. Struct. Concr. 2021. [CrossRef]

7. Ahmad, W.; Farooq, S.H.; Usman, M.; Khan, M.; Ahmad, A.; Aslam, F.; Al Yousef, R.; Al Abduljabbar, H.; Sufian, M. Effect of coconut fiber length and content on properties of high strength concrete. Materials 2020, 13, 1075. [CrossRef]

8. Afroughsabet, V.; Biolzi, L.; Ozbakkaloglu, T. High-performance fiber-reinforced concrete: A review. J. Mater. Sci. 2016, 51, 6517-6551. [CrossRef]

9. Shi, T.; Li, Z.; Guo, J.; Gong, H.; Gu, C. Research progress on CNTs/CNFs-modified cement-based composites-A review. Constr. Build. Mater. 2019, 202, 290-307. [CrossRef]

10. Khan, M.; Ali, M. Effectiveness of hair and wave polypropylene fibers for concrete roads. Constr. Build. Mater. 2018, 166, 581-591. [CrossRef]

11. Khan, M.; Cao, M.; Ali, M. Cracking behaviour and constitutive modelling of hybrid fibre reinforced concrete. J. Build. Eng. 2020, 30, 101272. [CrossRef]

12. Khan, M.; Ali, M. Effect of super plasticizer on the properties of medium strength concrete prepared with coconut fiber. Constr. Build. Mater. 2018, 182, 703-715. [CrossRef]

13. Khan, M.; Cao, M.; Xie, C.; Ali, M. Efficiency of basalt fiber length and content on mechanical and microstructural properties of hybrid fiber concrete. Fatigue Fract. Eng. Mater. Struct. 2021, 44, 2135-2152. [CrossRef]

14. Khan, M.; Cao, M.; Chaopeng, X.; Ali, M. Experimental and analytical study of hybrid fiber reinforced concrete prepared with basalt fiber under high temperature. Fire Mater. 2021. [CrossRef]

15. Li, L.; Khan, M.; Bai, C.; Shi, K. Uniaxial tensile behavior, flexural properties, empirical calculation and microstructure of multi-scale fiber reinforced cement-based material at elevated temperature. Materials 2021, 14, 1827. [CrossRef] [PubMed]

16. Ahmad, W.; Ahmad, A.; Ostrowski, K.A.; Aslam, F.; Joyklad, P. A scientometric review of waste material utilization in concrete for sustainable construction. Case Stud. Constr. Mater. 2021, 15, e00683. [CrossRef]

17. Ahmad, W.; Ahmad, A.; Ostrowski, K.A.; Aslam, F.; Joyklad, P.; Zajdel, P. Sustainable approach of using sugarcane bagasse ash in cement-based composites: A systematic review. Case Stud. Constr. Mater. 2021, 15, e00698. [CrossRef]

18. Lothenbach, B.; Scrivener, K.; Hooton, R.D. Supplementary cementitious materials. Cem. Concr. Res. 2011, 41, 1244-1256. [CrossRef]

19. Juenger, M.C.; Snellings, R.; Bernal, S.A. Supplementary cementitious materials: New sources, characterization, and performance insights. Cem. Concr. Res. 2019, 122, 257-273. [CrossRef]

20. Li, K.; Qin, M.; Gui, Q. Durability properties of structural concretes containing secondary cementitious materials. Green Mater. 2019, 7, 40-51. [CrossRef]

21. Tosti, L.; van Zomeren, A.; Pels, J.R.; Damgaard, A.; Comans, R.N. Life cycle assessment of the reuse of fly ash from biomass combustion as secondary cementitious material in cement products. J. Clean. Prod. 2020, 245, 118937. [CrossRef]

22. Diaz-Loya, I.; Juenger, M.; Seraj, S.; Minkara, R. Extending supplementary cementitious material resources: Reclaimed and remediated fly ash and natural pozzolans. Cem. Concr. Compos. 2019, 101, 44-51. [CrossRef]

23. De Matos, P.R.; Oliveira, J.C.P.; Medina, T.M.; Magalhães, D.C.; Gleize, P.J.P.; Schankoski, R.A.; Pilar, R. Use of air-cooled blast furnace slag as supplementary cementitious material for self-compacting concrete production. Constr. Build. Mater. 2020, 262, 120102. [CrossRef]

24. Shubbar, A.A.; Jafer, H.; Dulaimi, A.; Hashim, K.; Atherton, W.; Sadique, M. The development of a low carbon binder produced from the ternary blending of cement, ground granulated blast furnace slag and high calcium fly ash: An experimental and statistical approach. Constr. Build. Mater. 2018, 187, 1051-1060. [CrossRef]

25. Dananjayan, R.R.T.; Kandasamy, P.; Andimuthu, R. Direct mineral carbonation of coal fly ash for $\mathrm{CO}_{2}$ sequestration. J. Clean. Prod. 2016, 112, 4173-4182. [CrossRef]

26. Ukwattage, N.; Ranjith, P.; Yellishetty, M.; Bui, H.H.; Xu, T. A laboratory-scale study of the aqueous mineral carbonation of coal fly ash for $\mathrm{CO}_{2}$ sequestration. J. Clean. Prod. 2015, 103, 665-674. [CrossRef]

27. Şahmaran, M.; Li, V.C. Durability properties of micro-cracked ECC containing high volumes fly ash. Cem. Concr. Res. 2009, 39, 1033-1043. [CrossRef]

28. Lee, K.M.; Lee, H.K.; Lee, S.H.; Kim, G.Y. Autogenous shrinkage of concrete containing granulated blast-furnace slag. Cem. Concr. Res. 2006, 36, 1279-1285. [CrossRef]

29. Ahmad, A.; Farooq, F.; Niewiadomski, P.; Ostrowski, K.; Akbar, A.; Aslam, F.; Alyousef, R. Prediction of compressive strength of fly ash based concrete using individual and ensemble algorithm. Materials 2021, 14, 794. [CrossRef]

30. Su, M.; Zhong, Q.; Peng, H.; Li, S. Selected machine learning approaches for predicting the interfacial bond strength between FRPs and concrete. Constr. Build. Mater. 2021, 270, 121456. [CrossRef]

31. Nguyen, K.; Nguyen, Q.D.; Le, T.A.; Shin, J.; Lee, K. Analyzing the compressive strength of green fly ash based geopolymer concrete using experiment and machine learning approaches. Constr. Build. Mater. 2020, 247, 118581. [CrossRef]

32. Ahmad, A.; Farooq, F.; Ostrowski, K.; Śliwa-Wieczorek, K.; Czarnecki, S. Application of novel machine learning techniques for predicting the surface chloride concentration in concrete containing waste material. Materials 2021, 14, 2297. [CrossRef] [PubMed]

33. Ahmad, A.; Chaiyasarn, K.; Farooq, F.; Ahmad, W.; Suparp, S.; Aslam, F. Compressive strength prediction via gene expression programming (GEP) and artificial neural network (ANN) for concrete containing RCA. Buildings 2021, 11, 324. [CrossRef] 
34. Sufian, M.; Ullah, S.; Ostrowski, K.; Ahmad, A.; Zia, A.; Śliwa-Wieczorek, K.; Siddiq, M.; Awan, A. An experimental and empirical study on the use of waste marble powder in construction material. Materials 2021, 14, 3829. [CrossRef] [PubMed]

35. Machine Learning Repository, Center for Machine Learning and Intelligent Systems. Available online: https:/ / archive.ics.uci. $\mathrm{edu} / \mathrm{ml} /$ datasets / concrete+compressive+strength (accessed on 3 August 2007).

36. Yeh, I.-C. Modeling of strength of high-performance concrete using artificial neural networks. Cem. Concr. Res. 1998, 28, 1797-1808. [CrossRef]

37. Yeh, I.-C. Analysis of strength of concrete using design of experiments and neural networks. J. Mater. Civ. Eng. 2006, 18, 597-604. [CrossRef]

38. Yeh, I.C. Prediction of strength of fly ash and slag concrete by the use of artificial neural networks. J. Chin. Inst. Civil Hydraul. Eng. 2003, 15, 659-663.

39. Gandomi, A.H.; Roke, D.A. Assessment of artificial neural network and genetic programming as predictive tools. Adv. Eng. Softw. 2015, 88, 63-72. [CrossRef]

40. Ribeiro, M.H.D.M.; dos Santos Coelho, L. Ensemble approach based on bagging, boosting and stacking for short-term prediction in agribusiness time series. Appl. Soft Comput. 2020, 86, 105837. [CrossRef]

41. Dou, J.; Yunus, A.P.; Bui, D.T.; Merghadi, A.; Sahana, M.; Zhu, Z.; Chen, C.-W.; Han, Z.; Pham, B.T. Improved landslide assessment using support vector machine with bagging, boosting, and stacking ensemble machine learning framework in a mountainous watershed, Japan. Landslides 2020, 17, 641-658. [CrossRef]

42. Freund, Y.; Schapire, R.E.; Abe, N. A short introduction to boosting. J. Jpn. Soc. Artif. Intell. 1999, $14,1612$.

43. Ying, C.; Qi-Guang, M.; Jia-Chen, L.; Lin, G. Advance and prospects of AdaBoost algorithm. Acta Autom. Sin. 2013, 39, 745-758.

44. Farooq, F.; Ahmed, W.; Akbar, A.; Aslam, F.; Alyousef, R. Predictive modeling for sustainable high-performance concrete from industrial wastes: A comparison and optimization of models using ensemble learners. J. Clean. Prod. 2021, 292, 126032. [CrossRef]

45. Aslam, F.; Farooq, F.; Amin, M.N.; Khan, K.; Waheed, A.; Akbar, A.; Javed, M.F.; Alyousef, R.; Alabdulijabbar, H. Applications of gene expression programming for estimating compressive strength of high-strength concrete. Adv. Civ. Eng. 2020, 2020, 1-23. [CrossRef]

46. Ahmad, A.; Ostrowski, K.; Maślak, M.; Farooq, F.; Mehmood, I.; Nafees, A. Comparative study of supervised machine learning algorithms for predicting the compressive strength of concrete at high temperature. Materials 2021, 14, 4222. [CrossRef] 